Research Article

\title{
Investigation on mechanical properties and water absorbency of jute glass reinforced epoxy composite
}

\begin{abstract}
Fiber reinforced composite materials are attractive because of their properties such as high toughness, water resistance and can be adapted to meet the specific needs of a variety of applications. Incorporation of natural fibers can reduce the dependency over synthetic fibers. In this work, Jute glass fiber reinforced composites are fabricated by simple hand lay-up technique using epoxy resin as a matrix and various mechanical properties like tensile strength, flexural strength, impact strength and also the water absorption properties of the composite specimens are evaluated and analysed thoroughly. It is observed that incorporation of optimum amount of jute fibre with glass fibre improved mechanical properties can be achieved. Finally cost of composites are analysed and compared.
\end{abstract}

Keywords: Jute glass woven composites, water absorption, impact loading, hand layup
Volume 6 Issue 5 - 2020

\author{
Md Koushic Uddin, Muksit Ahmed \\ Chowdhury, Sonia Hossain, Md. Zahidul \\ Islam, Mohammad Shamim Sardar, Arnab \\ Singha Ami, Farhana Naowrin Tasnia \\ Department of Textile Engineering, Ahsanullah University of \\ Science \& Technology, Dhaka, Bangladesh
}

Correspondence: Md. Koushic Uddin, Assistant Professor, Ahsanullah University of Science and Technology, Dhaka, Bangladesh,Tel 01818252577,Email koushic_tex@aust.edu

Received: September 30, 2020 | Published: October 05, 2020

\section{Introduction}

A composite is a mixed material produced from two or more components constituting reinforcing matrix and a compatible matrix in order to achieve specific properties. ${ }^{1}$ Composite materials are popular because of its light weight, high strength, high design and shaped freedom ${ }^{2}$ and are used in many sectors such as armor, bullet proof jacket, protection for vehicle, car blanket, ballistic barrier, shelter for storage under special conditions. ${ }^{3}$ Glass fibre reinforced composite materials are common and used for wide variety of applications. 4.5 Glass fiber with epoxy resin gives the pleasing finishing and resistance to flammability. ${ }^{6}$ Natural fibers like jute exhibit superior mechanical properties are replacing the glass and carbon fibers recently owing to their easy availability easily bio degradable, renewable and low cost. $^{7,8}$

Kundu et al shows jute jute fibers are about seven to eight times lighter than steel ${ }^{9}$ and have proper tensile strength, high toughness, low extensibility and ensures better breathability of fabric. ${ }^{10}$ Ramesh et al. syudied on sisal-jute-glass fiber reinforced composites and suggested that it can improve the properties and used as an alternate material for glass fiber reinforced polymer composites. ${ }^{11} \mathrm{M}$ Boopalan et al. showed that addition of banana fiber in jute-epoxy reinforced hybrid composite results good mechanical and thermal properties. ${ }^{12}$ Moe Moe Thew and Kin Liao used short bamboo and glass fiber as reinforcement to polypropylene based matrices and improved the adhesion between fiber and matrix. ${ }^{13}$ Aleya Fardausy et al. investigated

Table I Specifications of the raw materials used on jute-poly vinyl chloride (PVC) composites and found good tensile strength. ${ }^{14}$ Polymer hybrid composites were prepared by hand layup method with an appropriate amount of epoxy and polyester resin mixture and Jute, Pineapple leaf and Glass fibers. ${ }^{15,16}$

Many researches have been done to incorporate the natural fibres as reinforcing agent to reduce the dependency of high priced glass fibre as it is not ecofriendly. Jute has the potential to be used as a replacement for traditional reinforcement materials in composites for application which requires high strength to weight ratio and further weight reduction. It has also high tensile strength, low extensibility and ensures breathability of fabrics. In this study, jute and glass fiber reinforced composites were fabricated varying different proportion by simple hand layup method and their mechanical performance has been investigated by experimentally.

\section{Experimental}

\section{Materials}

In this work, for fabricating the composites specimen $100 \%$ Jute and Glass woven fabrics are used. The fabrics are collected from the local market. The jute and glass fiber of bi-directional woven fabrics with $280 \mathrm{gm} / \mathrm{m}^{2}$ and $400 \mathrm{gm} / \mathrm{m}^{2}$ respectively are used for the fabrication of specimen. The Bisphenol based epoxy resin and HN 2200 type hardener are used. The specifications of the materials are presented in Table 1.

\begin{tabular}{l|l}
\hline Materials & Specifications \\
\hline Jute fibre & Bleached, woven bi-directional jute ( $100 \%$ jute), Weight $280 \mathrm{gm} / \mathrm{m}^{2}$ \\
Glass fibre & PTFE (Polytetrafluroethylene) coated white E-glass fiber in woven form, \\
Weight $400 \mathrm{gm} / \mathrm{m}^{2}$
\end{tabular}


Table continue

\begin{tabular}{|c|c|c|}
\hline Materials & Specifications & Samples \\
\hline Epoxy resin & $\begin{array}{l}\text { Bisphenol based epoxy resin, Chemical name - Bisphenol A di-glycidyl } \\
\text { ether, Chemical formula - } \mathrm{C}_{21} \mathrm{H}_{24} \mathrm{O}_{4}\end{array}$ & \\
\hline Hardener & $\begin{array}{l}\text { Colorless transparent liquid (HN-2200), Chemical name: Methyl-I, 2, 3, } \\
\text { 6-tetrahydrophthalic anhydride. }\end{array}$ & \\
\hline & Chemical formula $-\mathrm{C}_{9} \mathrm{H}_{10} \mathrm{O}_{3}$ & \\
\hline $\begin{array}{l}\text { High temperature } \\
\text { mold releasing wax }\end{array}$ & $\begin{array}{l}\text { It is a premium mold release formulated from a blend of hydrocarbon and } \\
\text { microcrystalline waxes. }\end{array}$ & \\
\hline
\end{tabular}

Table 2 Laminate stacking sequence

\begin{tabular}{|c|c|c|c|c|c|}
\hline \multirow{2}{*}{ Samples } & \multirow{2}{*}{ Stacking sequence } & \multirow{2}{*}{ Matrix \% } & \multicolumn{2}{|c|}{ Weight $\%$ of fibres (reinforcement) } & \multirow{2}{*}{$\begin{array}{l}\text { Thickness of composites } \\
(\mathrm{mm})\end{array}$} \\
\hline & & & jute & Glass & \\
\hline SI & נرل & 70 & 30 & 0 & 3.1 \\
\hline S2 & JG & & 20 & 10 & 2.5 \\
\hline S3 & GJG & & 10 & 20 & 2.1 \\
\hline S4 & GGG & & 0 & 30 & 1.5 \\
\hline S5 & JGJG & & 15 & 15 & 2.8 \\
\hline
\end{tabular}

\section{Composite fabrication process}

The fabrication process of the composites is carried out by conventional hand lay-up process. Here the glass and jute fibres are used as reinforcement and epoxy resin used as matrix. The corresponding hardener ( $\mathrm{HN}-2200)$ and epoxy resin was mixed in a proportion of 10:1 by percentage of weight. Composites of different compositions are prepared with reinforcement and matrix as $30 \%$ and $70 \%$ respectively by weight. The composite specimens were put under heavy load for about 24 hours and the curing carried out at room temperature. After the curing process the samples are cut with suitable dimensions for tests. Table 2 presents the laminate stacking sequence.

\section{Test methods}

Tensile test: Tensile test also known as a tension test is one of the most common types of mechanical testing where tensile force applies on a material to measure the specimen's response to the maximum stress. ${ }^{17}$ The fabricated composites are cut using a hand grinding machine to get the specific dimension (dog bone shape) for tensile testing as per ASTM:D638 standards. The schematic diagram of tensile test specimen is shown is Figure 1. The test was carried out using a universal testing machine (UTM) at a room temperature with $40 \%$ relative humidity. The tensile stress is recorded with respect to increase in strain. The specimen was placed in the grip of the tensile testing machine and the test is performed by applying tension until it undergoes fracture. The corresponding load and strain obtained are plotted on the graphs. Figure 2 presents the cut sample specimen for tensile test.

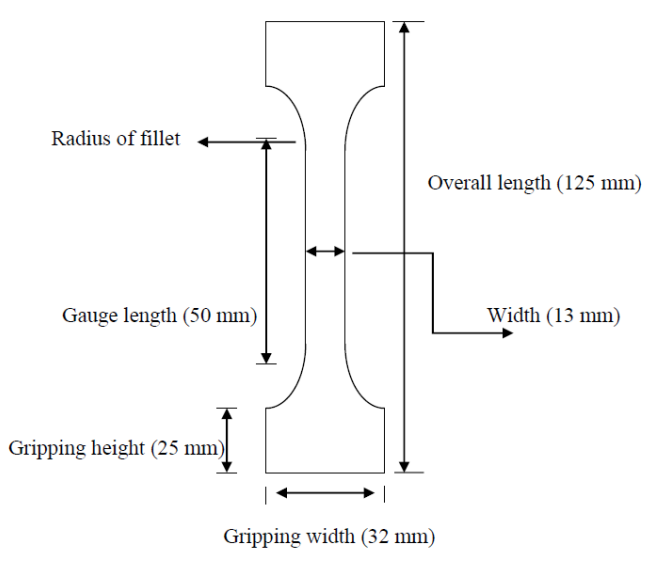

Figure I The schematic diagram of tensile test specimen.

Flexural test: The flexural test is performed on the same tensile testing machine (UTM) as per the ASTM: D790 standards. According to the standard test procedure the specimens are cut into $125 \mathrm{~mm}$ long, $12.7 \mathrm{~mm}$ wide and $3 \mathrm{~mm}$ thick. In this method, the outer rollers are $64 \mathrm{~mm}$ apart and specimens tested at a strain rate of $0.2 \mathrm{~mm} / \mathrm{min}$. The test is performed at room temperature. There are three different types of specimens are used in this test which are shown in Figure 3. The specimen is subjected to a load at its center between the supports and force is applied until it breaks. Flexural test determines the maximum stress induced in the outer most fibre. 


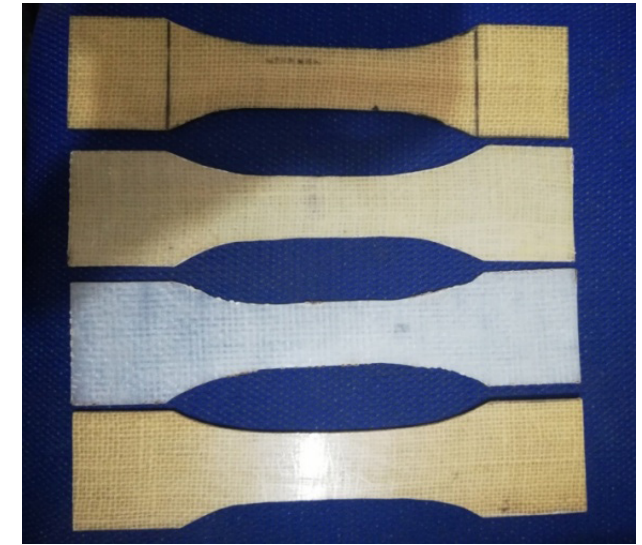

Figure 2 Specimen for tensile test.

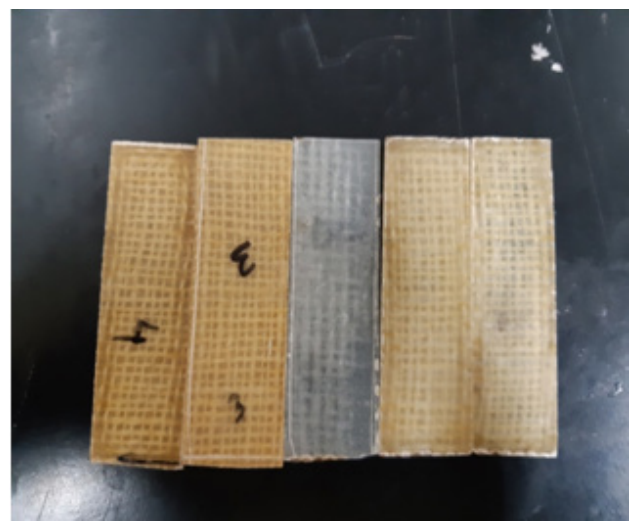

Figure 3 Specimen for flexural test.

Impact loading test: Impact strength is the capability of the material to withstand a suddenly applied load and is expressed in terms of energy. Izod impact strength test is used to measure the impact strength of composite samples by maintaining the standard ASTM D4812. The standard size of the specimen is $75 \times 10 \times 10 \mathrm{~mm}$. Figure 4 and Figure 5 presents the samples of impact loading test before and after respectively.

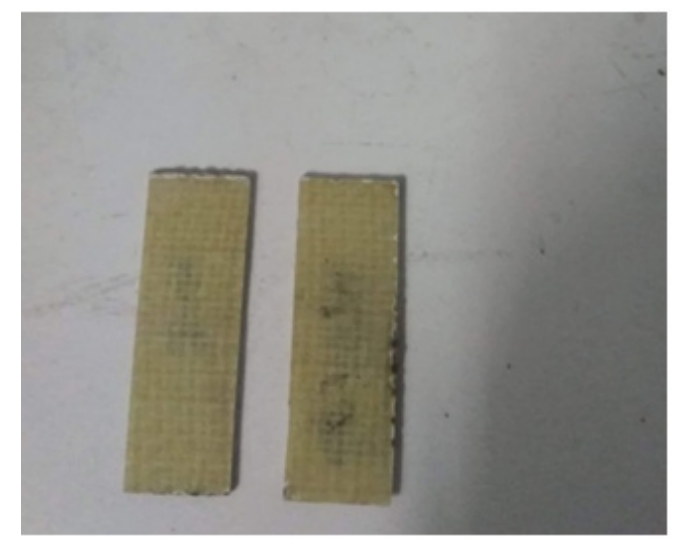

Figure 4 Specimen for impact loading test.

Water absorbency test: This test measures the amount of water absorbed by a specimen or a material under specified conditions. The water absorbency test is carried out according to ASTM D570 and specimens are cut into dimensions $76.2 \mathrm{~mm}$ in length and $25.4 \mathrm{~mm}$ in a width by a thickness of the panel. Figure 6 shows the schematic diagram of the specimen. First the specimens are dried in an oven for a specified time and temperature $\left(110^{\circ} \mathrm{C}\right)$ and then placed in desiccators to cool. Immediately after cooling the specimen are weighed. The material is then emerged in water for 2 and 24 hours. Finally the specimens are removed, patted dry with a lint free cloth, and weighed. Water absorption is expressed by weight percentage. The specimens for water absorbency test are shown in the Figure 7.

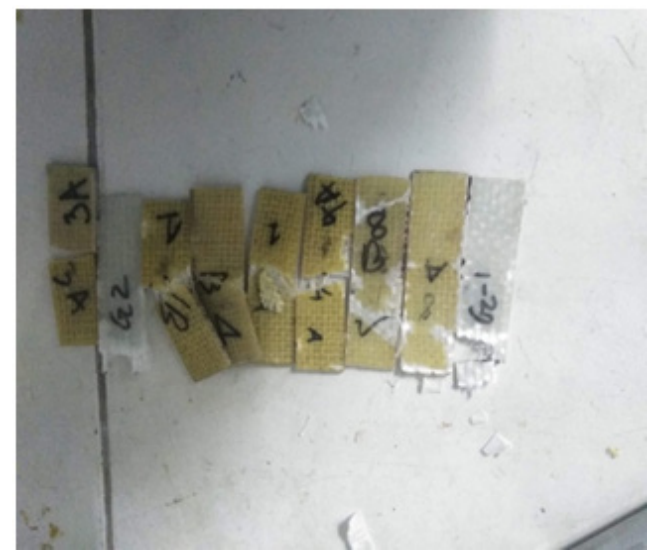

Figure 5 Specimens after impact loading test.

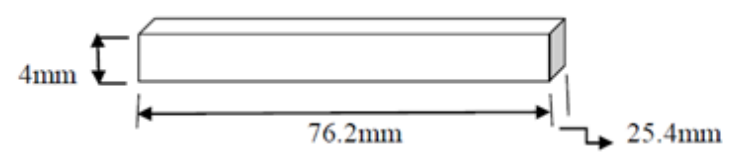

Figure $\mathbf{6}$ The schematic diagram of water absorbency test specimen.

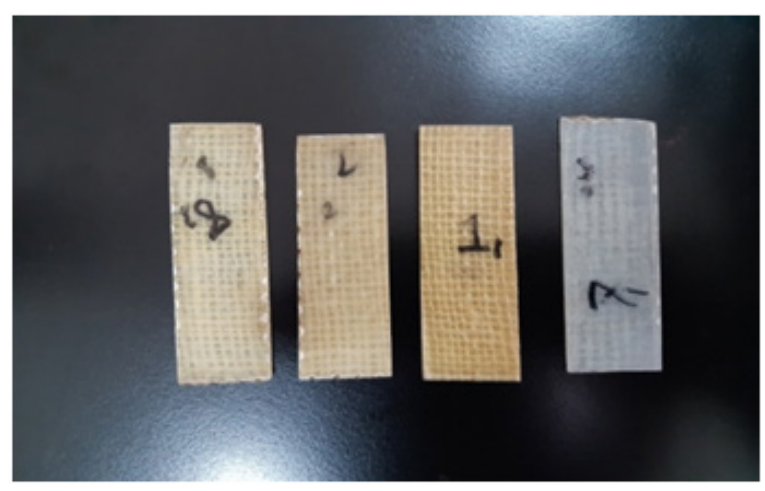

Figure 7 Specimen for water absorbency test.

\section{Results and discussion}

\section{Tensile properties}

The specimen samples of different compositions are tested in the Universal Testing Machine (UTM). The typical stress-strain graphs for samples S1, S2, S3, S4 and S5 are generated directly from the machine and are presented in Figure 8, Figure 9, Figure 10, Figure 11 and Figure 12 respectively. Experimental results of tensile strength of various composites with different weight ratio of reinforcement shown in Table 3.

Figure 13 represent the comparison of tensile strength of specimens. The highest tensile strength achieved in case of hybrid composite of four layers reinforcement and when glass fiber and jute fiber content were $15 \%-15 \%$ of weight of total $30 \%$ reinforcement which is composite S5. 
Table 3 Results of tensile strength

\begin{tabular}{|c|c|c|c|c|c|c|}
\hline Samples & $\begin{array}{l}\text { Stacking } \\
\text { sequence }\end{array}$ & Tensile Strength (MPa) & Elastic Modulus (MPa) & Energy $(J)$ & Maximum Force (KN) & Elongation (\%) \\
\hline SI & נرل & 50.7 & 2047 & 1.031 & 640 & 6.24 \\
\hline S2 & JGJ & 66.3 & 3612 & 4.174 & 1380 & 12.78 \\
\hline S3 & GJG & 129.8 & 1339 & 3.557 & 2180 & 6.24 \\
\hline S4 & GGG & 161.7 & IIII & 5.91 & 2552 & 9.54 \\
\hline S5 & JGJG & 218.1 & IIII & 5.91 & 2552 & 9.54 \\
\hline
\end{tabular}

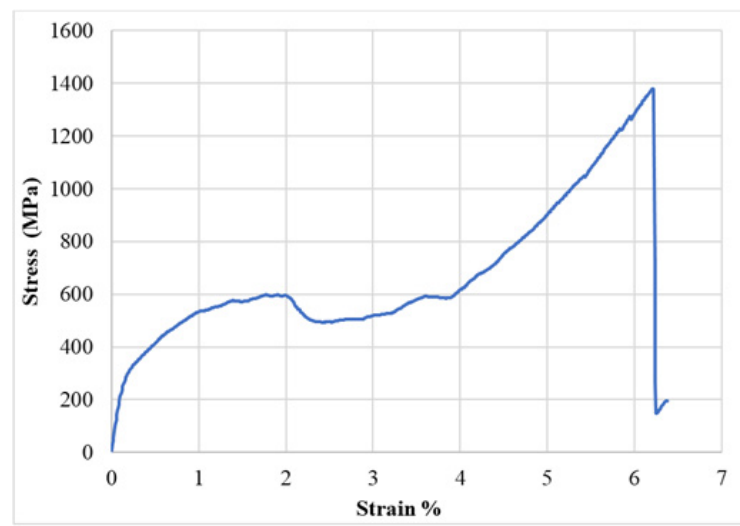

Figure 8 Stress strain curve for tensile test in JJJ composite.

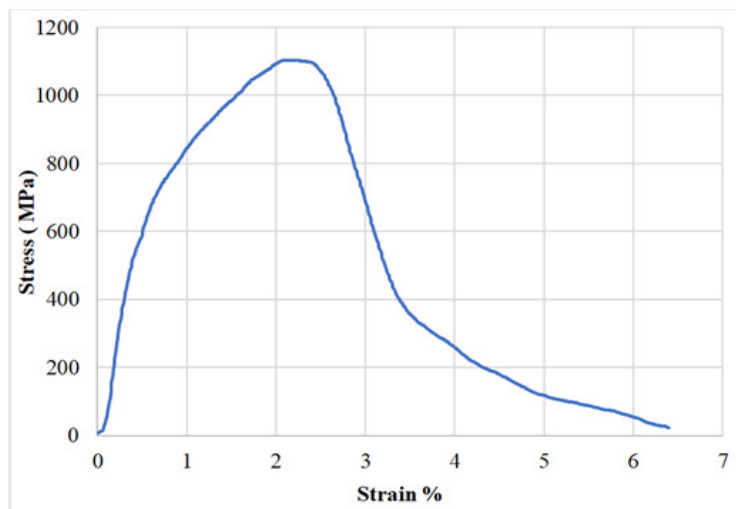

Figure 9 Stress strain curve for tensile test in JGJ composite.

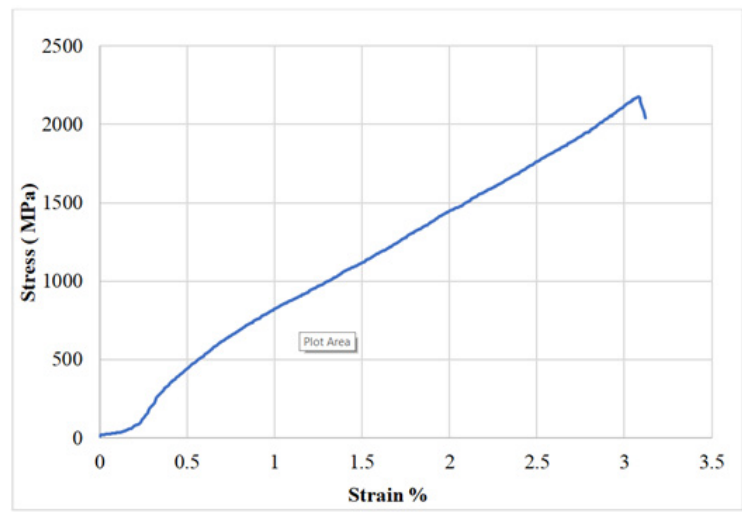

Figure 10 Stress strain curve for tensile test in GJG composite.

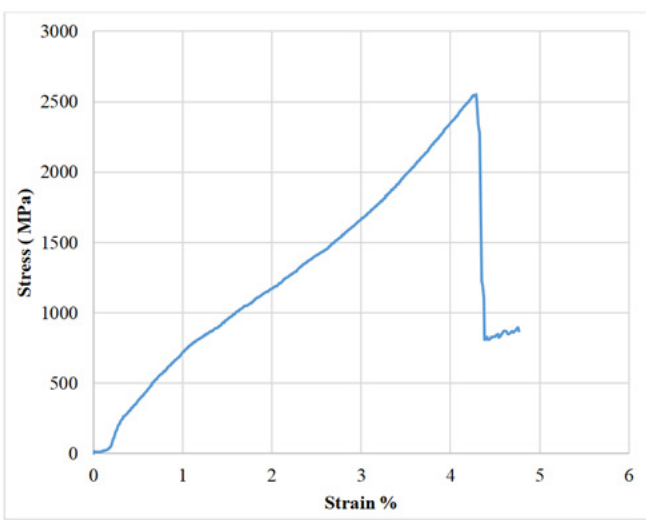

Figure II Stress strain curve for tensile test in GGG composite.

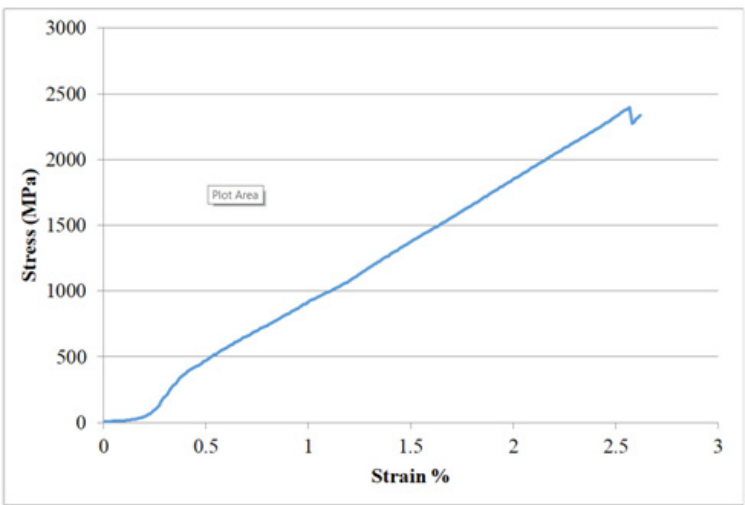

Figure 12 Stress strain curve for tensile test in JGJG composite.

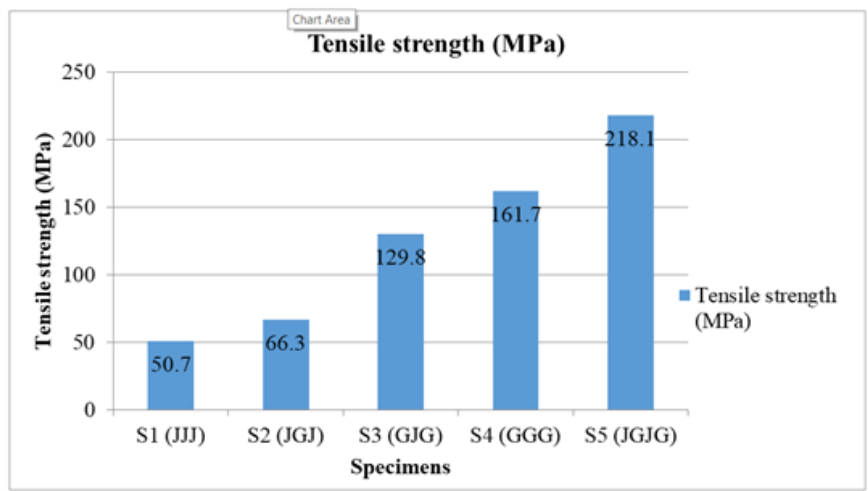

Figure I3 Representation of tensile strength of specimens.

Citation: Uddin MK, Chowdhury MA, Hossain S, et al. Investigation on mechanical properties and water absorbency of jute glass reinforced epoxy composite. J Textile Eng Fashion Technol. 2020;6(5): 190-197. DOI: 10.15406/jteft.2020.06.00250 
It is clear that the increasing amount of glass fibre increases the tensile strength of the composites. However, with the increasing of natural fiber content than synthetic fiber content, the overall tensile strength was decreased. Moreover, increasing of jute fiber reinforcement, the composite becomes more brittle as jute shows brittle behavior and overall strength decreases.

\section{Flexural properties}

The composite specimens for flexural test were prepared rectangular in shape and they were carried out in UTM machine in accordance with ASTM standard to measure the flexural strength of the samples. Load with respect to Cross Head Travel is plotted for the determination of flexural strength. The jute-glass fiber reinforced composite sample exhibits a significant difference in strength. The typical stress strain curve generated from machine for samples S1, S2, S3, S4 and S5 are presented in Figure 14, Figure 15, Figure 16, Figure 17 and Figure 18 respectively.

Table 4 presents the overall flexural properties of specimens. The flexural strength of jute-epoxy composite is lower than that of glassepoxy composites because jute fibers have less stiffness in comparison to glass. The composite gives better flexural strength by the addition of jute fiber with glass fibers than single reinforced composites which is shown in the Figure 19.

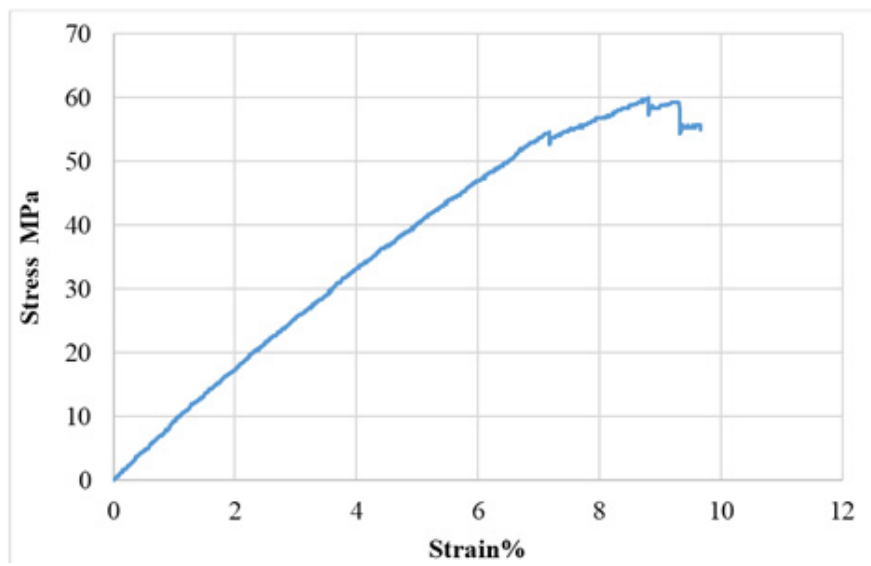

Figure I4 Stress strain curve for flexural test in J J composite.

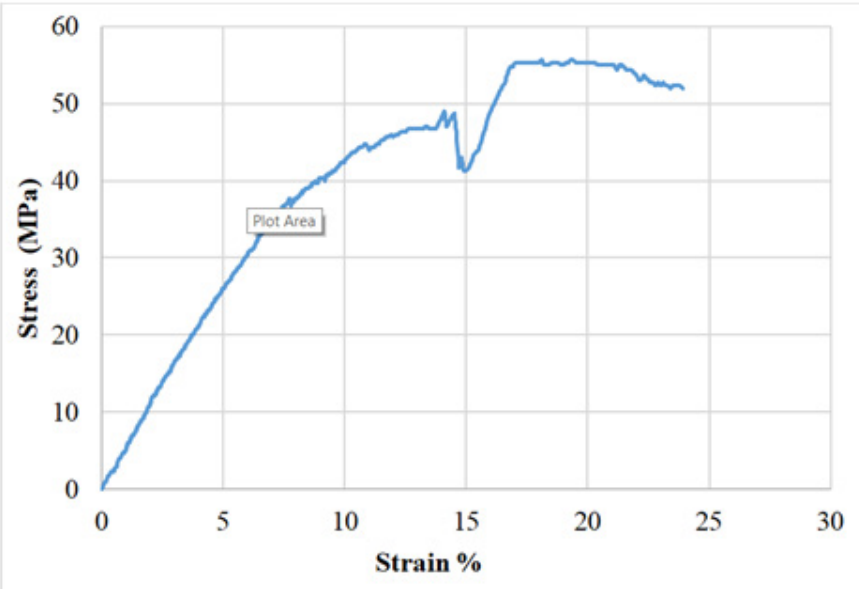

Figure 15 Stress strain curve for flexural test in JGJ composite.

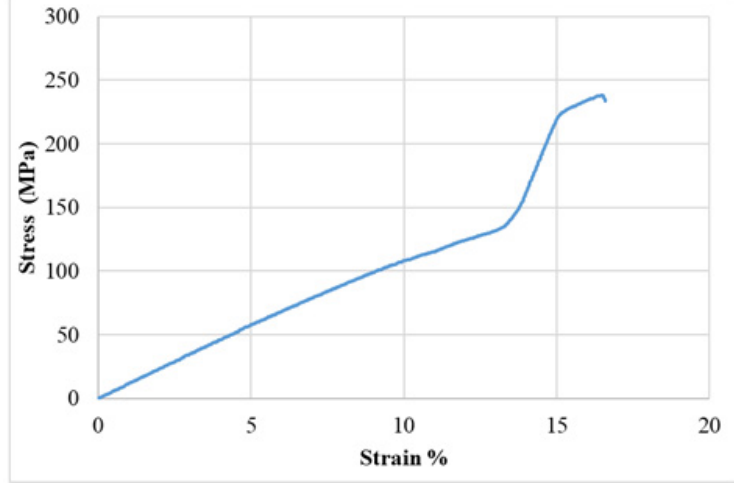

Figure 16 Stress strain curve for flexural test in GJG composite.

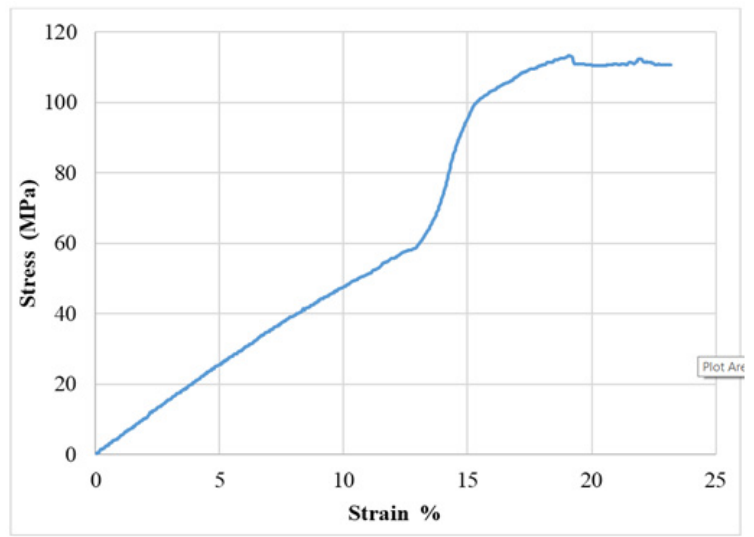

Figure 17 Stress strain curve for flexural test in GGG composite.

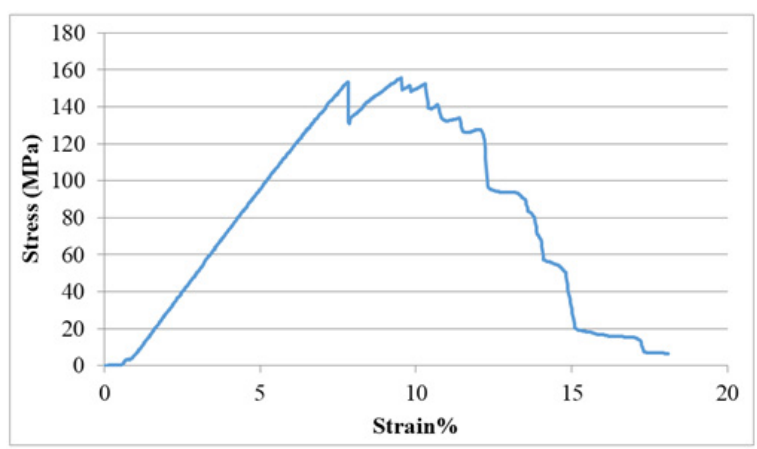

Figure 18 Stress strain curve for flexural test in JJ composite.

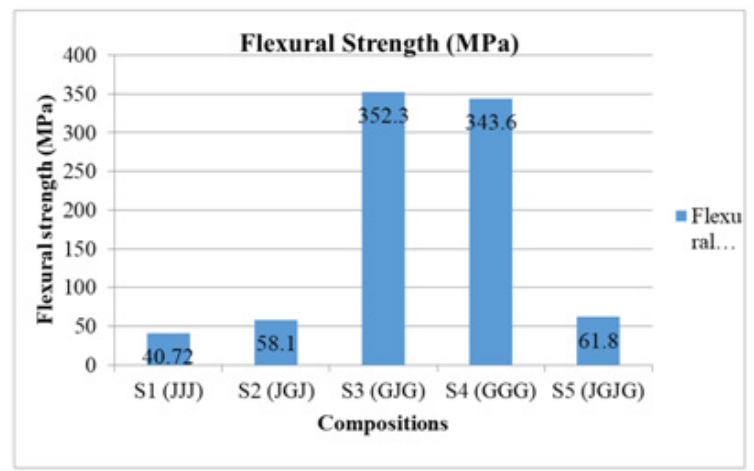

Figure 19 Representation of flexural strength of specimens. 
Table 4 Results of Flexural strength

\begin{tabular}{lllllll}
\hline Samples & $\begin{array}{l}\text { Stacking } \\
\text { sequence }\end{array}$ & Flexural Strength (MPa) & Strain (\%) & Energy (J) & Young's Modulus (MPa) & Maximum Force (N) \\
\hline SI & JJ & 40.72 & 1.637 & 0.2044 & 3720 & 60.1 \\
S2 & JGJ & 58.1 & 2.715 & 0.15165 & 3740 & 55.7 \\
S3 & GJG & 352.3 & 2.076 & 0.925 & 13165 & 355 \\
S4 & GGG & 343.6 & 1.719 & 0.3978 & 16614 & 640 \\
S5 & JGJG & 61.8 & 2.285 & 0.84 & 3650 & 72 \\
\hline
\end{tabular}

\section{Impact strength properties}

The impact strength properties of different composites are shown in the Table 5 .

The results indicated that the maximum impact strength is obtained for hybrid composites followed by $15 \%$ glass and $15 \%$ jute fiber composites as in Figure 20. However, jute composite exhibit low performance compared to other composites. On increasing the amount of jute content, which is more brittle than glass fiber, the overall brittleness of material increases and impact strength decreases. But the optimum amount of natural fiber addition with glass fiber can improve the overall impact strength of the composite.

\section{Absorbency test result}

All the specimens were carried out for water absorbency test by maintaining ASTM Standard and calculated the absorbency test in percentage shown in Table 6 and Figure 21.
It is visible that the overall better water resistance was shown by $30 \%$ of glass fabric content of total reinforcement which is $0.15 \%$ and $0.57 \%$ after 2 hours and 24 hours of wetting respectively. It is because of epoxy resin improves the bonding between the glass fabric and matrix and increase inter bonding strength. As a result the chance of absorption of water is reduced. The water absorbency increases with the addition of jute fiber content thus the water resistance reduced because natural fibers tend to be more absorbent than synthetic ones.

\section{Cost analysis}

Figure 22 presents the cost of composites for making 1 square feet. Only material costs are included. The cost of composite material reduced with the increasing number of jute fiber content. Fiber glass is an expensive fiber material due to its high cost manufacturing process. It was found that natural fiber jute can be a partial replacement of high cost glass fiber and the total cost can be reduced to a certain extent.

Table 5 Impact Strength properties of specimens

\begin{tabular}{llllll}
\hline Samples & $\begin{array}{l}\text { Stacking } \\
\text { sequence }\end{array}$ & Specimen Energy $(J)$ & Specimen E/W $(J / m m)$ & Pendulum energy $(J)$ & ${\text { Impact strength }\left(J / \mathbf{m m}^{2}\right)}$ \\
\hline SI & JJ & 7.585 & 3.214 & 10.028 & 0.156 \\
S2 & JGJ & 6.055 & 3.52 & 10.028 & 0.166 \\
S3 & GJG & 8.008 & 3.742 & 10.028 & 0.169 \\
S4 & GGG & 5.891 & 3.386 & 10.028 & 0.16 \\
S5 & JGJ & 6.84 & 4.071 & 10.028 & 0.186 \\
\hline
\end{tabular}

Table 6 Absorbency test result of the specimens

\begin{tabular}{lllll}
\hline Immersion Time & Sample & Dried sample weight $(\mathbf{g m})$ & Wet sample weight $(\mathbf{g m})$ & Water absorbency (\%) \\
\hline & S1 & 3.57 & 3.58 & 0.28 \\
2 -hours & S2 & 4.95 & 4.96 & 0.2 \\
& S3 & 5.08 & 5.09 & 0.19 \\
& S4 & 6.48 & 6.49 & 0.15 \\
& S5 & 6.22 & 6.23 & 0.16 \\
& S1 & 3.99 & 4.08 & 2.25 \\
& S2 & 4.37 & 4.45 & 1.83 \\
& S3 & 4.95 & 5 & 1 \\
& S4 & 7 & 7.04 & 0.57 \\
& S5 & 6.2 & 6.25 & 0.8 \\
\hline
\end{tabular}




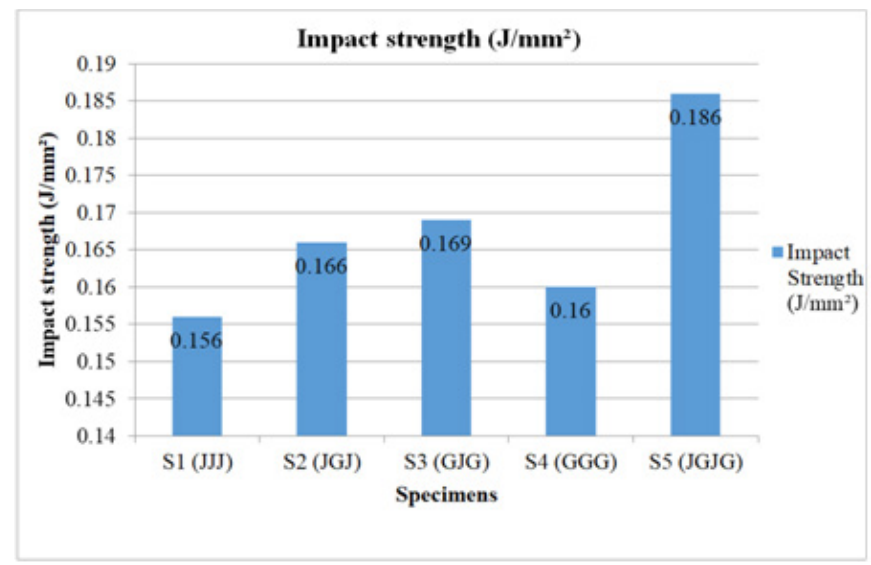

Figure 20 Representation of Impact strength of specimens.

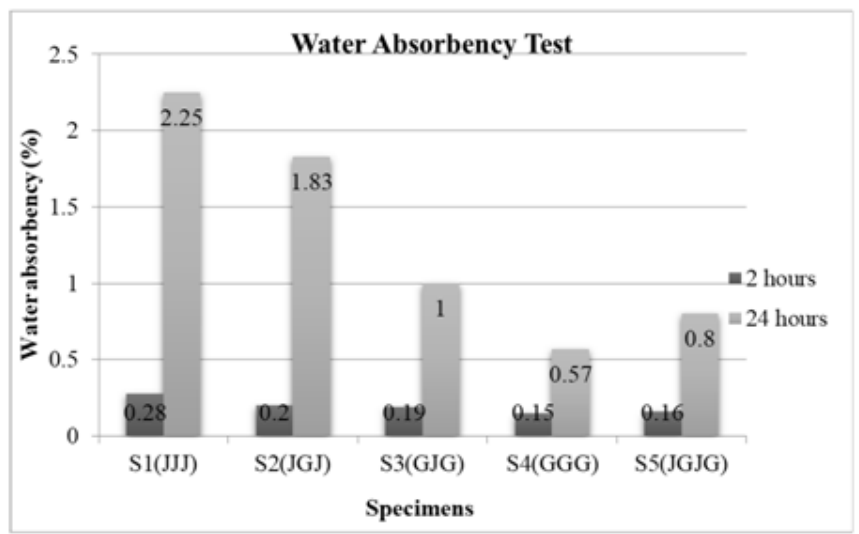

Figure 2I Representation of water absorbency o the composites.

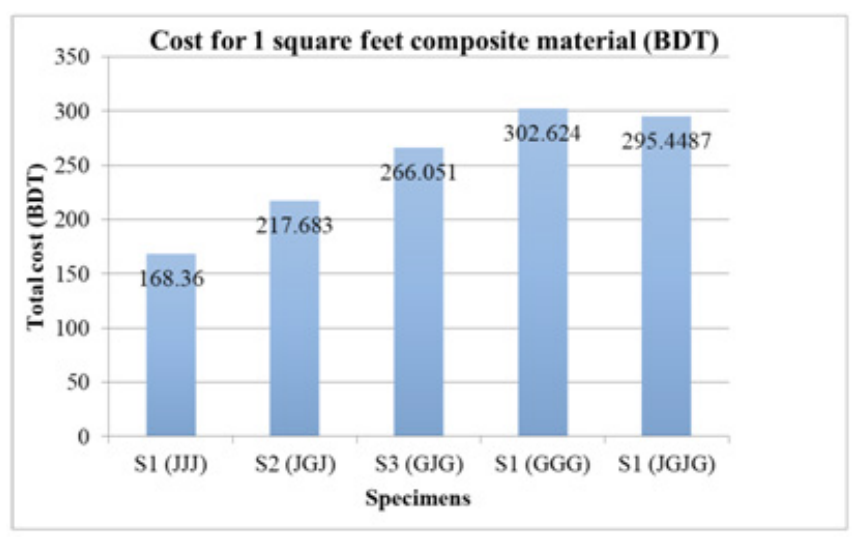

Figure 22 Presentation of cost analysis.

\section{Conclusion}

This work showed that by incorporating the optimum amount of natural fibers, the overall strength of glass fiber reinforced hybrid composite can be increased. It is observed that in making of composites for low load bearing applications, jute fiber can be a partial replacement of high cost synthetic fibers. Due to high stiffness and impact strength of Jute reinforced glass epoxy composite, it has good damage tolerance, lighter weight, good surface finish \& appearances, weight reduction hence higher fuel efficiency, so they would enjoy wider applications in automobiles and railway coaches and sporting goods such as skis, canoe helmets. However, due to less water absorption, glass-epoxy reinforced composite can be used for door application such as insulated indoor and outdoor, underground piping, tanks, washroom door etc.

\section{Acknowledgments}

None.

\section{Funding}

None.

\section{Conflicts of interest}

The authors have no conflicts of interest regarding the publication of this paper.

\section{References}

1. Lubin G. Handbook of composites. Springer Science \& Business Media; 2013.

2. Zhang L. The application of composite fiber materials in sports equipment. In 2015 International Conference on Education, Management, Information and Medicine. Atlantis Press; 2015.

3. Luz FS, Monteiro SN, Lima ES, et al. Ballistic application of coir fiber reinforced epoxy composite in multilayered armor. Materials Research. 2017;20:23-28.

4. MR S, Arpitha GR, Yogesha B. Investigation on mechanical property evaluation of jute-glass fiber reinforced polyester. IOSR Journal of Mechanical and Civil Engineering. 2014;11(4):50-57.

5. Saleh MA. The study of impact response of composite material. Doctoral dissertation, UMP; 2008. 54 p.

6. Soutis C. Fibre reinforced composites in aircraft construction. Progress in aerospace sciences. 2005;41(2):143-151.

7. Ramesh M, Palanikumar K, Reddy KH. Comparative evaluation on properties of hybrid glass fiber-sisal/jute reinforced epoxy composites. Procedia Engineering. 2013;51:745-750.

8. Pujari S, Ramakrishna A, Kumar MS. Comparison of jute and banana fiber composites: A review. International Journal of Current Engineering and Technology. 2014;2(2):121-126.

9. Kundu SP, Chakraborty S, Roy A, et al. Chemically modified jute fibre reinforced non-pressure (NP) concrete pipes with improved mechanical properties. Construction and Building Materials. 2012;37:841-850.

10. Jha K, Samantaray BB, Tamrakar P. A study on erosion and mechanical behavior of jute/e-glass hybrid composite. Materials Today: Proceedings. 2018;5(2):5601-5607.

11. Ramesh M, Palanikumar K, Reddy KH. Mechanical property evaluation of sisal-jute-glass fiber reinforced polyester composites. Composites Part B: Engineering. 2013;48:1-9.

12. Boopalan M, Niranjanaa M, Umapathy MJ. Study on the mechanical properties and thermal properties of jute and banana fiber reinforced epoxy hybrid composites. Composites Part B: Engineering. 2013;51:5457.

13. Thwe MM, Liao K. Characterization of bamboo-glass fiber reinforced polymer matrix hybrid composite. Journal of materials science letters. 2000;19(20):1873-1876.

14. Fardausy A, Kabir MA, Kabir H, et al. Study of physical, mechanical and thermal properties of unidirectional jute fiber reinforced PVC film composites. International Journal of Advanced Research in Engineering and Technology (IJARET). 2012;3(2):267-274. 
15. Reddy MI, Kumar MA, Raju CR. Tensile and flexural properties of jute, pineapple leaf and glass fiber reinforced polymer matrix hybrid composites. Materials today: proceedings. 2018;5(1):458-462.

16. Magarajan U, Arvind D, Kannan N, et al. A comparative study on the static mechanical properties of glass fibre vs glass-jute fibre polymer composite. Materials Today: Proceedings. 2018;5(2):6711-6716.
17. Kori Y, Kitagawa K, Hamada H. Crystallization behavior and viscoelasticity of bamboo-fiber composites. Journal of applied polymer science. 2005;98(2):603-612. 